\title{
Amnion Membrane Graft Dressing in Superficial Partial Thickness Burn in Pediatric Patients
}

\author{
Md Saif Ullah' \\ K MN Ferdous ${ }^{*}$ \\ Md Mobassar Hussain Mullick ${ }^{2}$ \\ Md Rashedul Alam' \\ Md Sazzaduar Rahman' \\ A R Khan' \\ 'Department of Pediatric Surgery \\ Dhaka Shishu (Children) Hospital \& \\ Bangladesh Institute of Child Health (BICH) \\ Dhaka, Bangladesh. \\ ${ }^{2}$ Gano Sastho Hospital \\ Dhaka, Bangladesh.
}

*Correspondence to:

\section{Dr. Kazi Md. Noor-Ul Ferdous}

Registrar

Department of Pediatric Surgery

Dhaka Shishu (Children) Hospital \& Bangladesh Institute of Child Health (BICH)

Dhaka, Bangladesh.

Mobile: +8801711322487

E-mail:kmnferdous@gmail.com

http://www.banglajol.info/index.php/CMOSHMCJ

\begin{abstract}
Objective: The aim of this study was to find out the effectiveness of amniotic membrane graft dressing in the treatment of superficial partial thickness burn in children. Methods: The retrospective study was conducted on the patients admitted with superficial partial thickness burn in the burn unit of Dhaka Shishu Hospital age 0-12 years, during the period from January 1999 to December 2011. All of them treated with amnion membrane graft dressing. Results: Total 370 patients were included in this study. Mean age was 2.76 years. Amnion dressing suppresses bacteria in the wound as well as reduced infection. Amnions have good adherent characteristics, which reduced infection as well as reduction of oozing of plasma from the wound, that become dry early. It has a role on burnt pain reduction, Frequency of dressing change, rate of healing, cost, duration hospital stay. Conclusion: Our experience showed that amniotic membrane is one of the effective biological skin substitutes used in burn wounds, with efficacy of low bacterial counts, has advantageous of reducing protein loss, electrolytes \& fluids. Decreasing the risk of infection minimizing pain, accelerate of wound healing and good handling properties. It is ready available does not present immunological problem and allergies response. It is cost effective and very helpful for developing countries.
\end{abstract}

Key words: Amnion Membrane Graft Dressing; Superficial partial thickness burn; Pediatric Patients

\section{INTRODUCTION}

Burn is the most common injury among the children in developing countries. It is the second most common cause of accidental death in USA under five year's children. It occurs more in the low socio economic people. Burn child require the service of multi disciplinary team and may extended over many years ${ }^{1}$.

It is important to find out an appropriate material for dressing of burn wounds that helps healing and is readily available, easily applicable and economical. It is also protective from infection and dissection. Therefore reducing the expense of burn treatment is an important aim and healing of the burn wound is the primary goal ${ }^{2}$.

Last several years near about two decades have witnessed more progress on our knowledge of the patho-physiology of thermal injury as well as the improvement in the management than before. Finally initial care of the burn wound is the most important treatment with accompanying shock ${ }^{3}$.

Infection is the commonest problem for the healing processes in burn wound. Majority causes it can be overcome by strict environment control maintained in burn unit, early excision of dead skin and the use of effective tropical antimicrobial agents. Another factor which improves healing of any burn wound is passive evaporative water, heat $\operatorname{loss}^{3}$.

The rate of loss is proportional to the surface area of burn and depth of burn. Evaporative fluid and heat loss can be prevented by immediate coverage of the wound with allograft or xeno graft ${ }^{3}$. 
Human amniotic membrane is admirably suited for this purpose and has many advantages. ${ }^{3}$ The amniotic membrane has been used since 1910 with variable success as a material for burn injury coverage ${ }^{4}$. It can be collected as large size and easily available. Its preparation is easy as well as applicable also. It is non-reactive and it reduces $15 \%$ water loss. Finally histological structure is same to the skin $^{5}$.

There are two verities of amniotic membra.ne can be used in burn dressing one is in Toto (amnio \& chorionic) for the deep burn, and only amnion (the epithelium basal membrane) for superficial burn ${ }^{4}$.

The amnion is a thin semitransparent tissue forming the inner most layers of the fetal membrane. A fresh amnion carries contamination and may cause disease transmission. Usually the amnion is collected from the placenta of selected and screened donor. It can be preserved in different way-like cryopreservative liquid nitrogen, Silver nitrate. Storage in antibiotic solution. Glycerol preservative sheets, Dried Sheets and gamma irradiated sheets ${ }^{6}$.

In collaboration with the International Atomic Energy Agency a project on tissue banking of radiation sterilized graft has been started at the Institute of Food and Radiation biology of Bangladesh Atomic Energy Commission. Radiation sterilized amniotic membrane graft have been prepared at the genetic division institute of food and radiation biology. We have collected these graft from Atomic Energy Research Establishment, Saver, Dhaka.

\section{MATERIALS AND METHODS}

This retrospective study was done from January 1999 to December 2012, for a period of 12 years in the Department of Pediatric \& Burn - Reconstructive Surgery, Dhaka Shishu Hospital (DSH). We included the neonates, infants and children (0 to 12 years), irrespective of sex, admitted for superficial partial thickness burn. Electric burn, deep partial thickness burn, Full thickness burn were excluded.

\section{Processing steps of Freeze/ Oven Dried Amnion Membrane} Grafts:

Post-delivery fresh amniotic sacs were collected aseptically from labor and operation room. It separate from chorion and washed thoroughly first with sterile distilled water to remove blood other mucilaginous substances, then shaking with sterile normal saline using mechanical shaker, spreading on sterile surgical gauze and placed on plastic from / freeze drying /Oven drying. Finally packed with triple packing, labeling and sealing under laminar flow cabinet. Sterilization at $25 \mathrm{kGy}$ by gamma irradiation. These grafts were supplied to burn unit of for clinical use [Figure 1]

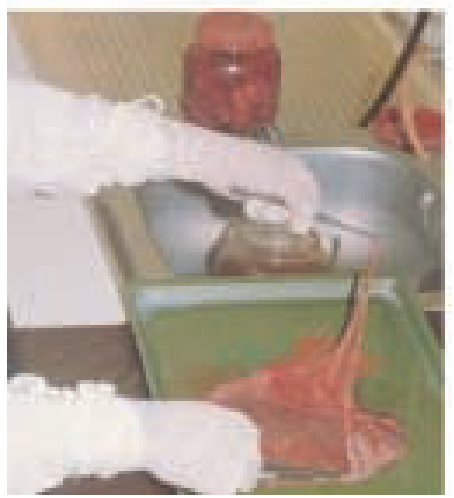

Figure 1 : Preparing amniotic membrane from placenta

\section{TREATMENT PROTOCOL}

Immediately after admission, resuscitation was done with intravenous (IV) fluid. Analgesics were used, other general treatment like perentaral antibiotics, oral $\mathrm{H}_{2}$ blocker (Renitidine), Antihistamines, high protein diet was given. First dressing was done under general anaesthesia, wound cleaned with normal saline and then amniotic membrane graft applied. Initially applied amniotic graft covered with role bandage for twenty four hour to fixing the graft. Then dressing kept open.

The following data obtained from departmental records bookage, sex, date and time of occurrence of injury, percentage of the body surface area burned, sources of injury. Others parameters which were also analyzed in relation to wound cover included- duration of reducing pain after dressing, cessation of oozing of plasma, day of adhesion, time of healing, frequency of dressing change, infection and hospital stay.

\section{RESULTS}

Total 370 patients were included in this study retrospectively. Age ranged from 15 days to 12 years, mean age 2.76 years. Most of the patients $257(69.5 \%)$ were within 1 to 6 years and then $17 \%$ from 6 to 12 years of age. [Figure 2]

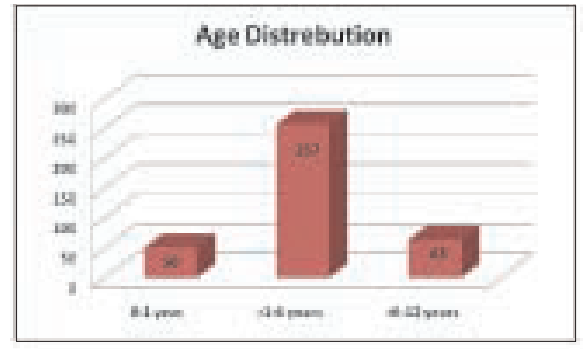

Figure 2 : Age Distribution of the study group

Male patients were $231(62.4 \%)$ and female patients 139 (37.6\%). All patients were admitted in the hospital within half an hour to six hours of burn injury without having any first aid. We have observed amniotic membrane grafts had good adhesive properties. Adhesion occurred within 24 hours. Wound became dry earlier by preventing oozing of plasma in all the cases within this time.

The study cases demonstrated that range of duration of healing were 7-15 days, mean 9.2 days. 325 patients $(87.8 \%)$ healed within 12 days and 45 patients within 15 days. [Figure $3 \mathrm{a}, \mathrm{b}$ ]

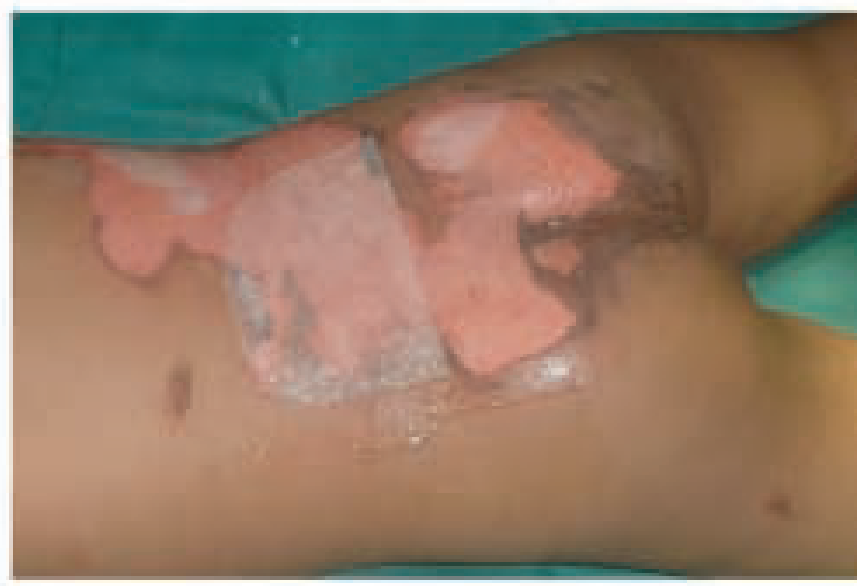

Figure 3a : Applying amniotic membrane graft 


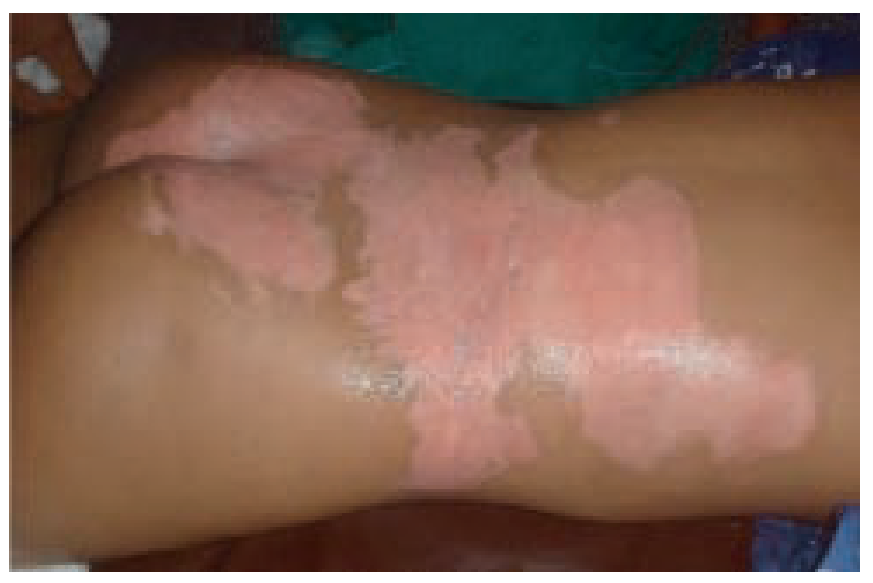

Figure 3b : After removing amniotic membrane graft (Healed burn wound)

It was seen that amnion membrane dressing burnt patients needed less analgesics for pain reliever. Most of them did not need extra analgesics.

Average dressing changes among study group only 1.15 times, ranged 1-3 times.

Thirty patients $(8.1 \%)$ developed wound infection, proven by culture reports. These patients needed dressing change 2 to 3 times and hospital stay time increased.

Dressing with amnion membrane graft is much more cost effective than any other imported dressing materials. We got amnion graft from Bangladesh Atomic Energy Commission totally free of cost.

Hospital stay among study cases ranged from 10 to 17 days and mean 12.13 days. 221 (59.7\%) patients stayed up to 12 days, 119 patients stayed 13-15 days and 30 patients more than 15 days.

\section{DISCUSSION}

The main goal in the management of an open wound is to obtain a clean and closed wound in the shortest time. The search for an ideal wound cover as a substitute for patients' skin began more than an century ago and continues today.

It has been claimed to be one of the most effective biological skin substitutes used in burn wound is amniotic membrane ${ }^{5}$.

In this study was carried out on 370 patients aged 0-12 years who had partial thickness superficial burn and admitted and treated in Dhaka Shishu Hospital Burn unit. Male are more prone to burn than female. This result was similar to the studys $^{7}$. Early childhood group age $>1-6$ years are more common which is supported by him ${ }^{8}$.

They observed that increased rate of re-epithelisation of partial thickness superficial burn by the use of amniotic membrane ${ }^{4}$. This stimulatory effect of on epithelisation \& has been considered to be mediated by growth factors and progenic for cell released by amniotic membrane ${ }^{9,10,11}$.
In this study this property very well noticed. Usually the partial thickness burn needs healing time up to 14 days. By the use of amniotic membrane duration of healing average time is below 10 days.

Antibacterial property is an important feature of amniotic membrane and is thought to be due to the presence of antibodies and Lysoxyne (a bacteriolytic protein) in amniotic membrane ${ }^{12}$. Amniotic membrane has got a high thrombin activity which allows a rapid and efficient attachment of amniotic membrane to a wound surface ${ }^{12,13}$. This close adherence allows restoration of lymphatic integrity which protects circulating phagocytise from exposure and allows removal of surface debris and bacteria ${ }^{14}$.

Furthermore, adherence wound surface preventing exposure state of the wound which reduces the bacterial count ${ }^{4,15,16}$. In this study showed absence of wound infection in most of the cases. We got wound infection only in thirty patients. Most of them presented with contaminated wound.

The reduction of wound exudates is significant in amniotic membrane wound coverage than conventional wound dressing and without dressing wound ${ }^{17}$. It also observed in our study that amniotic membrane grafts had good adhesive properties. Adhesion occurred within 24 hours. Wound became dry earlier by preventing oozing of plasma in all the cases within this time.

There is a well-recognised property of amniotic membrane to relieve pain when it is used as skin substitute, relieving of pain is due to decreased inflammation, better stat hydration of wound bed \& prevention of the exposed nerve endings from external agents which causes pain ${ }^{18-21}$. Similar result also observed in this study.

Angeoenisis is another effect which is important for wound healing. This is noted by them to using amniotic membrane ${ }^{22}$. This property also observes in this study.

Amnion dressing was highly cost effective in our study, as we got it free of cost, which is agreed with same other studies ${ }^{18,23-25}$.

Amnion dressing reduced in hospital stay in this study. It is corresponds others studies ${ }^{8,24,25}$.

\section{CONCLUSION}

Amniotic membrane is one of the effective biological skin substitutes used in burn wounds, with efficacy of low bacterial counts. It also has advantageous of fluid loss, decreasing the risk of infection, minimizing pain, accelerate of wound healing and good handling properties. It is ready available, does not present immunological problem and allergies response. It is cost effective. It is very effective for management of burn in developing countries.

\section{DISCLOSURE}

All the authors declared no competing interest. 


\section{REFERENCES}

1. Sharp R J. Burns, paediatric surgry, Ashcraft, KW., 2 ed, Philadelphia: WB Saunders Company.1993; 89-102.

2. Ravishanker R, Bath A.S., Roy R. Amnion Bank-the use of long term glycerol preserved amniotic membranes in the management of superficial and superficial partial thickness burns. Burns. 2003;29:369-374.

3. Bose B. Burn wound dressing with amniotic membrane. Annals of the Royal College of Surg. Of England. 1979; 61:444-447.

4. Robson MC, KrizekTJ, Koss N,Samburg JL. Amniotic membrane as a temporary wound dressing . Surg Gynaccol Ob stet.1973;136:904-906.

5. Hadjiiki O, Anatassov N. Amniotic membranes for temporary burn coverage. Annals of Burns and fire disasters. 1996; 10:2-7.

6. SukariHalim A, Khoo T.L, Mohd. YussofSh. J.Biologic and Synthetic skin substitute: An overview. Indian J Plast Surg. 2010;43(suppl):S23-S28.

7. Saadallah M, Al Fzacko, Falah G. Sharif. The effectiveness of amniotic membrane as a biological dressing on the donor site of the split thickness skin graft. Annals of the college of Medicine, Mosul. 2006; 32(1\&2): 29-32.

8. Mullick M M H. Comparison of Amnion Membrane graft dressing and Silver Sulfadiazine application in Superficial Partial Thickness Burn in Children up to 12 years of age. MS Thesis. Bangladesh Institute of Child Health. The University of Dhaka. 2000; 63-67.

9. Isabelle Mermet, Nathalie Pottier, Jean Marie Sainthiller, malugani, Sandrive Cariey-Remonnay et al.Use of amniotic membrane transplantation in the treatment of venous leg ulcers. Wound Rep Reg. 2007;15:459-464.

10. Horch RE, Kopp J, Kneser U,Beier J, bach AD. Tissue engineering of cultured skin substitutes .J Cell mol Med. 2005;9:592-608

11. Bailo M. Soncini M, Vertua E, Signoroni PB, Sanzone S,Lombardi G, Arienti D, Calamani F, Zatti D, Paul P, Albertini A, Zorzi F, Cavagnini A, Candtti F, Wengler GS, Parolini o, Engraftment potential of human amnion and chorion cells derived from term placenta, Transplantation. 2004; 78: 439-448.

12. Walker AB, Use of Amniotic membranes for wound coverage in Wise DL (ed) Burn Wound coverings, Boca Raton: CRC Press. 1984;60.

13. Gantra MA. Amniotic Membrane in Surgery. Journal of Pakistan Medical Association January 2003.

14. Sawhney CP: Amniotic Membrane as a biological dressing in the management of burns. Burns. 1989; 15 (5): 339-342.

15. Robson MC and Kerizek TJ, The effect of Human amniotic membranes on the bacterial population of infected rat burns . Ann Surg. $1973 ; 177: 144-149$.

16. Quinby WC, Hoover HC, Scheflan M, et ai. Clinical Trials of amniotic membranes in burn wound care . Plast Reconstr Surg. 1982 ; 70:711.

17. Hanumanthappa M B. Gopinathan S. Guruprasad R D. Amniotic membrane dressing varsus conventional dressing in lower limb varicose ulcer: A prospective comparative study. Int. J Biol Med Res. 2012; 3(2): 1616-1620.

18. Sharma SC, Bagree MM, Bhat et al. Amniotic membrane is an effective burn dressing material . Jpn Surg. $1985 ; 15(2): 140$

19. Kasi N, Durrani KM, Siddiqui MA, Human amniotic membrane as a versatile biological dressing. A preliminary report. J Pak Med Assoc. 1987; 37-:290.

20. Rao TV, Chandrasekharam V. Human amnion as a dressing material in burns . Indian J Surg. 1981;43: 561.

21. Dino BR, Eufemio GG, Devilla MS, Human Amnion : the establishment of an amnion bank and its practical application in surgery . J Philippine Med Asso. 1966 ;42:230.

22. Faulk WP, Matthews RN, Stevens PJ, et al, Human amnion as an adjunct in wound healing . Lancet. $1980 ; 1: 1156$.

23. Gruss S.S and Jirsch D.W. Human amniotic Membrene, a versatile wound dressing. Can Med Assoc J. 1978;118(10):123-146.

24. Piserchia N E. and Akenzuagi Amniotic membrene dressing for burns in children.Acheap method of treatment for developing countries.Trop Geogr Med. 1981; 33 (3): 235-240.

25. Khan A R, Jamaly M H, Nessa A, Begum A and Islam MS. Tissue banking Utilization of oven dred radiation sterilized amniotic membrane graft for treatmentof burn patient in Bangladesh, a preliminary report. Dhaka Shishu (Children) Hosp J. 1989;5:10-13. 